\title{
Pharmacist-Driven Multidisciplinary Initiative Continuously Improves Overall Inpatient Medication Safety in Tertiary Care Hospital through Medication Tracer Methodology
}

\author{
Sachin Raval*, Nipul Kapadia, Sanket shah, Rajkumar Sharma, Jignesh Prajapati \\ Department of Pharmacy, Apollo Hospitals International Limited, Plot No, 1A, Gandhinagar - Ahmedabad Rd, GIDC \\ Bhat, Bhat, Ahmedabad, Gujarat 382428, India
}

\section{*Corresponding Author}

Sachin Raval

\section{Article History}

Received: 13.06 .2020

Accepted: 11.07.2020

Published: 16.07.2020

\begin{abstract}
Medication management is complex process. It is very potential process for the patient safety. Recent JCI STUDY published (March 13, 2019), in 2018, The Joint Commission reviewed a total of 801 sentinel events. Medication errors are the 10 most frequently reported types of sentinel events in 2018. The main aim of study is to smoothening of medication management process. In this process there are many persons involves like Doctor, Nurses, Pharmacists, Hourse keeping, and PCA. Initially we were nothing in medication safety....even we didn't know about medication safety in details... We read the standards of NABH, JCI and Pharmacie de qualite....there are so many improvement scope for medication safety in our hospitals...we done 6 NABH Audit, 2 JCI Audit and 4 Pharmacie De Qualite Audit for continuous improvement of medication safety in hospitals. For continuous review of the medication-use process and to assess compliance with Medication Management Standards. We did the audit of various parameters of medication management as per JCI Standards. We took comparative data of 2018-19 and 2019-20. We made Google form and collect the data and compare the data.. we found significant improvement from this tracer methodology. Now a day this tracer method is habit in our institute. Implementing this proactive strategy will improve the ability of institutions to continuously review the medication-use system in various practice areas and identify deviations in policy and practice. Consistency and continuous follow up for this audit is very most important tool for safe medication practices.
\end{abstract}

Keywords: Medication use process, JCI Standards, Tracer methodology, Medication safety.

\section{INTRODUCTION}

\section{Medication error defined as...}

"A medication error is any preventable event that may cause or lead to inappropriate medication use or patient harm while the medication is in the control of the health care professional, patient, or consumer [1].

\section{Worldwide scenario on medication safety....}

- Global scenario of medication safety

The third WHO Global Patient Safety Challenge: Medication Without Harm...Unsafe medication practices and medication errors are a leading cause of injury and avoidable harm in health care systems across the world. Globally, the cost associated with medication errors has been estimated at \$42 billion USD annually [2].

- $\quad$ Recent JCI STUDY published (March 13, 2019)

- In 2018, The Joint Commission reviewed a total of 801 sentinel events. Medication errors are the 10 most frequently reported types of sentinel events in 2018 .

- Indian scenario of medication safety

Copyright @ 2020: This is an open-access article distributed under the terms of the Creative Commons Attribution license which permits unrestricted use, distribution, and reproduction in any medium for non commercial use (NonCommercial, or CC-BY-NC) provided the original author and source are credited. 
- A Harvard study by Prof Jha shows that 5.2 million medical errors are happening in India annually. Similarly the British Medical Journal quoted that India like any other developing country is recording a lot of medical errors. The reason behind this is that we have not trained doctors and nurses to measure the clinical outcomes.

NABH chapter MOM states that implementation of MOM Standard for overall improvement of medication safety in hospitals it includes selection and procurement, storage, prescription, indenting and dispensing, Administration and monitoring....

\section{Reason for Audit}

We implemented NABH Standards in 2011 in our hospitals....and JCI Standard in 2016...and Pharmacie De qualite standard in $2017 \ldots$.

All above accreditation for medication safety in hospitals... initially we were nothing in medication safety....even we didn't know about medication safety in details... We read the standards of NABH, JCI and Pharmacie de qualite....there are so many improvement scope for medication safety in our hospitals...we done 6 NABH Audit, 2 JCI Audit and 4 Pharmacie De Qualite Audit for continuous improvement of medication safety in hospitals [3].

In every audit we learnt some new things regarding medication safety....that's why we decided that this is continue process...Continuous Patient Safety and Medication Safety is most important behind this audit......our drug and therapeutic committee decided to do the Medication tracer in different wards/ICUs....on daily basis.... which is check list base....

\section{Criteria}

- $\quad$ Covered all the inpatient which takes medication management.

- Covered all the area of medication management...like Prescription, Storage, Indenting, Dispensing, Administration and Monitoring.

- Include Doctors, Nurses, Pharmacist, Housekeeping and top management...

\section{Standard Set and Rational}

- Need of this study was discussing in Drug \& Therapeutic committee...

- One standard procedure was set for medication tracer audit.

- Training was given to pharmacist for audit.

- Drug and Therapeutic committee approved Medication Tracer form initially...

- Than after we did this audit online---with the help of Google Form...

- Paper less initiative also taken in this project....

\section{Preparation and Planning}

- This project was started in April 2018....

- Top management also informed for Medication tracer audit.

- Also informed to Nursing head and Medical superintendent for this audit..

- Initial basis we made one Medication Tracer form (Hard Copy) and our all the ward pharmacist done this audit and data enter into the System..

- After July-2019...we made Google Form (Soft Copy) for this Medication Tracer...

- On daily basis we did this audit and analyze data on every 15 days..

- After immediate audit....our pharmacist train to Nursing staff, Doctor and Housekeeping..

\section{Methodology}

- Daily Morning we meet to the ward pharmacist and give task for audit in different places of hospitals.

- Ward pharmacist do the audit with observation of various management of medication parts (MOM), File checking, Medication room checking, Temperature Checking, refrigerator checking..

- Pharmacist also go with the nursing staff at the time of administration..

- $\mathrm{He} / \mathrm{she}$ also observe to the nursing staff about explain the medication, 7R and Patient monitoring..

- Initially our ward pharmacist manually do this audit..

- On daily basis do the medication tracer in different wards/ICUs.

- We also involve Nurses, Doctor and Housekeeping staffs.

- We covered all the areas of medication safety in this tracer.

- Following points covered while medication tracer audit.

$>$ Medication reconciliation 
$>$ Prescription

$>$ Drug order legible or not

$>$ Unapproved abbreviation

$>$ SNDT

$>$ Drug, dose, route, frequency

$>$ Stop order policy

$>$ Indication written in STAT/SOS Order

$>$ Concentrated electrolyte checking

$>$ Unit dose system

$>$ Independent double checking

$>$ Diabetic chart

$>$ Appropriateness review

$>$ Dispense LASA/HIGH ALERT Medicines with labels

$>$ Medication room temperature / Refrigerator temperature

$>$ Open on / discard on label

$>$ Cleaning of medication drawer/room

$>$ Storage of LASA \& HIGH ALERT Medications

$>$ 7R Follow

$>$ Prepared medicines labels

$>$ Two identifier checked (UHID/PATIENT NAME)

$>$ Medication explain at the time of administration

$>$ Medication effect monitoring for adverse drug reaction..

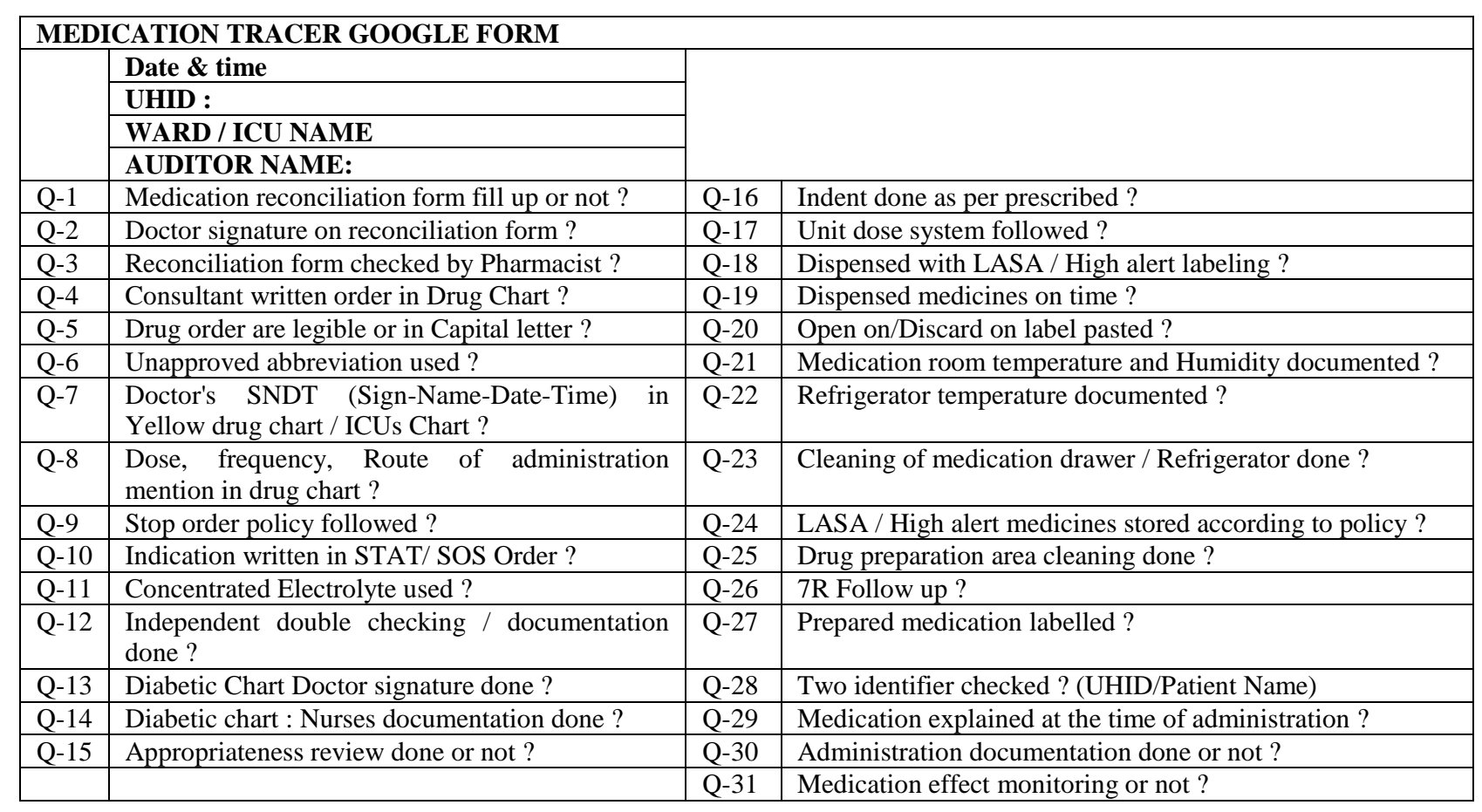

\section{Exclution Criteria}

- This is study is sample base analysis, daily 10 patient on random basis were analyzed during study period.

- Accident and emergency and routine dialysis patient s were excluded from study.

\section{DATA COLLECTION \\ PHASE I}

- As per NABH / JCI / Pharmacie DE QUALITE Guidelines we done the check list base audit "Medication Tracer Audit" during the period of April-2018 to March - 2019.....

- We collected 496 Medication Tracer in period of Aprtil-2018 to March-2019

- We analyze this data and some finding are discussed in D \& T Committee... 


\begin{tabular}{|c|c|c|c|c|c|c|}
\hline \multicolumn{7}{|c|}{ Medication Tracer @PATIENT CARE AREA April-18 to March-19 } \\
\hline \multicolumn{2}{|r|}{ Medication Reconciliation } & \multirow{2}{*}{$\begin{array}{l}\text { TOTAL } \\
496\end{array}$} & \multirow{2}{*}{$\begin{array}{l}\text { NC } \\
31\end{array}$} & \multirow{2}{*}{$\begin{array}{l}\text { C } \\
465\end{array}$} & \multirow{2}{*}{$\begin{array}{l}\% \mathrm{NC} \\
6.25\end{array}$} & \multirow{2}{*}{$\begin{array}{l}\text { \% C } \\
93.75\end{array}$} \\
\hline 1 & Medication reconciliation form fill up or not? & & & & & \\
\hline 2 & Doctor signature on reconciliation form? & 496 & 15 & 481 & 3.02 & 96.98 \\
\hline 3 & Reconciliation form checked by Pharmacist? & 496 & 30 & 466 & 6.05 & 93.95 \\
\hline 4 & Consultant written in Drug Chart & 391 & 230 & 161 & 58.82 & 41.18 \\
\hline 5 & Drug order are legible or in Capital letter? & 495 & 45 & 450 & 9.09 & 90.91 \\
\hline 6 & Unapproved abbreviation used? & 438 & 119 & 319 & 27.17 & 72.83 \\
\hline 7 & $\begin{array}{l}\text { Doctor's SNDT (Sign-Name-Date-Time) in Yellow drug chart / ICUs } \\
\text { Chart? }\end{array}$ & 495 & 19 & 476 & 3.84 & 96.16 \\
\hline 8 & Dose, frequency, Route of administration mention in drug chart? & 494 & 30 & 464 & 6.07 & 93.93 \\
\hline 9 & Stop order policy followed? & 407 & 84 & 323 & 20.64 & 79.36 \\
\hline 10 & Indication written in STAT/ SOS Order? & 385 & 34 & 351 & 8.83 & 91.17 \\
\hline 11 & Concentrated Electrolyte & 173 & 15 & 158 & 8.67 & 91.33 \\
\hline 12 & Diabetic Chart & 321 & 29 & 292 & 9.03 & 90.97 \\
\hline 13 & Appropriateness review done or not & 495 & 10 & 485 & 2.02 & 97.98 \\
\hline 14 & Indent as per prescribe & 496 & 5 & 491 & 1.01 & 98.99 \\
\hline 15 & Qty indent as per policy & 494 & 1 & 493 & 0.2 & 99.8 \\
\hline 16 & Indent on time or not & 494 & 8 & 486 & 1.62 & 98.38 \\
\hline 17 & Urgent \& Regular indent properly done or not & 492 & 5 & 487 & 1.02 & 98.98 \\
\hline 18 & Medicine dispense on time or not & 402 & 17 & 385 & 4.23 & 95.77 \\
\hline 19 & Qty Dispense as per indent & 402 & 3 & 399 & 0.75 & 99.25 \\
\hline 20 & Labeling (LASA, HIGH ALERT, CHEMICAL, ANTIBIOTIC) & 425 & 20 & 405 & 4.71 & 95.29 \\
\hline 21 & Open on \& Discard on labeling done or not & 462 & 36 & 426 & 7.79 & 92.21 \\
\hline 22 & Medicine store in proper tempreature or not & 496 & 28 & 468 & 5.65 & 94.35 \\
\hline 23 & Cleaning of medication drawer and Refrigerator done or not & 496 & 178 & 318 & 35.89 & 64.11 \\
\hline 24 & Room Tempreature and Refrigerator tempreature documented or not & 496 & 23 & 473 & 4.64 & 95.36 \\
\hline 25 & Medication store according to policy or not & 496 & 121 & 375 & 24.4 & 75.6 \\
\hline 26 & Drug Preparation area clean or not & 492 & 204 & 288 & 41.46 & 58.54 \\
\hline 27 & 7 R Follow or not & 495 & 48 & 447 & 9.7 & 90.3 \\
\hline 28 & Labeling of prepared Drugs done or not & 448 & 28 & 420 & 6.25 & 93.75 \\
\hline 29 & Two identifier check or not & 471 & 67 & 404 & 14.23 & 85.77 \\
\hline 30 & Use of medication explain or not & 453 & 160 & 293 & 35.32 & 64.68 \\
\hline 31 & Administration documented or not & 485 & 19 & 466 & 3.92 & 96.08 \\
\hline 32 & Medication effect monitor or not & 490 & 45 & 445 & 9.19 & 90.81 \\
\hline
\end{tabular}

\section{FINDINGS}

After first phase we found following deficiency in the system......that we discussed in D \& T Committee..

1. Consultant written in Drug Chart $-41.18 \%$ Compliance

2. Unapproved abbreviation used ? $-72.83 \%$ Compliance

3. Stop order policy followed ? $-79.36 \%$ Compliance

4. Cleaning of medication drawer and Refrigerator done or not $-64.11 \%$ Compliance

5. Medication store according to policy or not (LASA \& HIGH ALERT MEDICINES STORE AT WARD LEVEL) - $75.60 \%$ Compliance

6. Drug Preparation area clean or not $-58.54 \%$ Compliance

7. Two identifier check or not $-85.77 \%$ Compliance

8. Use of medication explain or not $-64.68 \%$ Compliance

- D \& T Committee discussed about deficiency and decided that more focus on above points to be covered in next phase audit.

- Also we covered new points like Independent double checking as per NABH (MOM) and JCI (MMU) Standards..

\section{RECOMMENDATIONS \\ PHASE II}

As per the finding of phase 1 study, All that data presented in Drug \& Therapeutic Committee meeting and probable solutions are planed and trained staff for the same.

- Main focus on deficiency points while tracer....

- Train all the Ward Pharmacist regarding Tracer audit. 
- Training given to all the Ward doctor / ICUs Registrar and Consultant for prescription writing rules..

- Medication Tracer report every 15 days Presented in Morning Huddle in Board room in present of Chief Operating officer and all the HODs.....

- Find out the possible solution on every 15 days..

- Training given on regular basis to the concern person for improvement of medication safety in hospitals.

- On job training given to Nurses and doctor...

- Exhibition on medication safety displayed all the time in ganesh atrium..for practicle awareness on medication safety.

- Emphasis the medication safety and to developed strict culture to follow preventive measure and ensure medication safety in every step.

- Discuss reports in DTC regularly and published hospital wide to ensure awareness.

- Error wise and stage wise analysis of all medication error. (complete CAPA of errors)

- New preventive measure develop with active participation of Medication and Nursing heads like, i) RTPA, ii) Medication tracer, iii) MMU tracer, iv) System Modifications (Special features in Medmantra) v) Speak program for medication safety vi) Medication Safety Training

Follow Up and Evaluation of Changes

- Our Top Management also takes excellent initiative in this audit due to improve the medication safety in hospitals.

- Every 15 days Medication tracer audit present in Board room presentation...

- All the stack holder DMS/MS, Nursing head, Pharmacy Head, Housekeeping head, Engineering head present In this presentation.

- Head of hospitals and DMS / MS...Gives input on audit findings.

- Awareness among doctors, Nurses and pharmacist definitely increased.

- All the stack holder more aggressively work due to this audit..

IMPACT OF AUDIT

\begin{tabular}{|c|c|c|c|c|c|}
\hline \multicolumn{6}{|l|}{ Medication Tracer @PATIENT CARE AREA } \\
\hline \multicolumn{6}{|l|}{ APR-19 to DEC-19 } \\
\hline MMU POINTS & TOTAL & NC & C & $\% \mathrm{NC}$ & $\% \mathrm{C}$ \\
\hline Medication reconciliation form fill up or not? & 521 & 15 & 506 & 2.88 & 97.12 \\
\hline Doctor signature on reconciliation form? & 521 & 8 & 513 & 1.54 & 98.46 \\
\hline Reconciliation form checked by Pharmacist? & 521 & 6 & 511 & 1.15 & 98.85 \\
\hline Consultant written in Drug Chart & 520 & 222 & 298 & 42.69 & 57.31 \\
\hline Drug order are legible or in Capital letter? & 505 & 25 & 481 & 4.95 & 95.05 \\
\hline Unapproved abbreviation used? & 519 & 9 & 510 & 1.73 & 98.27 \\
\hline Doctor's SNDT (Sign-Name-Date-Time) in Yellow drug chart / ICUs Chart? & 521 & 28 & 493 & 5.37 & 94.63 \\
\hline Dose, frequency, Route of administration mention in drug chart? & 521 & 14 & 507 & 2.69 & 97.31 \\
\hline Stop order policy followed? & 312 & 49 & 269 & 15.71 & 84.29 \\
\hline Indication written in STAT/ SOS Order? & 339 & 32 & 307 & 9.44 & 90.56 \\
\hline Concentrated Electrolyte used? & 74 & 1 & 73 & 1.35 & 98.65 \\
\hline Independent double checking / documentation done ? & 200 & 13 & 190 & 6.50 & 93.50 \\
\hline Diabetic Chart Doctor signature done? & 202 & 8 & 194 & 3.96 & 96.04 \\
\hline Diabetic chart : Nurses documentation done? & 215 & 11 & 204 & 5.12 & 94.88 \\
\hline Appropriateness review done or not? & 512 & 1 & 511 & 0.20 & 99.80 \\
\hline Dispensed with LASA / High alert labeling ? & 167 & 4 & 164 & 2.40 & 97.60 \\
\hline Dispensed medicines on time? & 504 & 7 & 496 & 1.39 & 98.61 \\
\hline Open on/Discard on label pasted? & 307 & 16 & 291 & 5.21 & 94.79 \\
\hline Medication room temperature and Humidity documented ? & 521 & 9 & 512 & 1.73 & 98.27 \\
\hline Refrigerator temperature documented ? & 521 & 5 & 516 & 0.96 & 99.04 \\
\hline Cleaning of medication drawer / Refrigerator done ? & 521 & 59 & 464 & 11.32 & 88.68 \\
\hline LASA / High alert medicines stored according to policy? & 172 & 26 & 146 & 15.12 & 84.88 \\
\hline Drug preparation area cleaning done ? & 521 & 56 & 465 & 10.75 & 89.25 \\
\hline 7R Follow up ? & 521 & 43 & 478 & 8.25 & 91.75 \\
\hline Prepared medication labelled? & 486 & 8 & 478 & 1.65 & 98.35 \\
\hline Two identifier checked ? (UHID/Patient Name) & 521 & 51 & 470 & 9.79 & 90.21 \\
\hline Medication explained at the time of administration? & 518 & 91 & 427 & 17.57 & 82.43 \\
\hline Administration documentation done or not? & 521 & 10 & 511 & 1.92 & 98.08 \\
\hline Medication effect monitoring or not? & 521 & 56 & 465 & 10.75 & 89.25 \\
\hline
\end{tabular}

- $\quad$ After analyze the data for 2018-19 and 2019-20........we got the following result. 


Project Improvement Sheet
\begin{tabular}{|l|l|l|}
\hline MMU POINTS & $\mathbf{2 0 1 8 - 1 9}$ & $\mathbf{2 0 1 9 - 2 0}$ \\
\hline Consultant written in Drug Chart & 41.18 & 57.31 \\
\hline Unapproved abbreviation used ? & 72.83 & 98.27 \\
\hline Stop order policy followed ? & 79.36 & 84.29 \\
\hline Concentrated Electrolyte used ? & 91.33 & 98.65 \\
\hline Cleaning of medication drawer / Refrigerator done? & 64.11 & 88.68 \\
\hline LASA / High alert medicines stored according to policy ? & 75.76 & 84.88 \\
\hline Drug preparation area cleaning done ? & 58.54 & 89.25 \\
\hline Two identifier checked ? (UHID/Patient Name) & 85.77 & 90.21 \\
\hline Medication explained at the time of administration ? & 64.68 & 82.43 \\
\hline Drug order are legible or in Capital letter ? & 90.91 & 95.05 \\
\hline
\end{tabular}

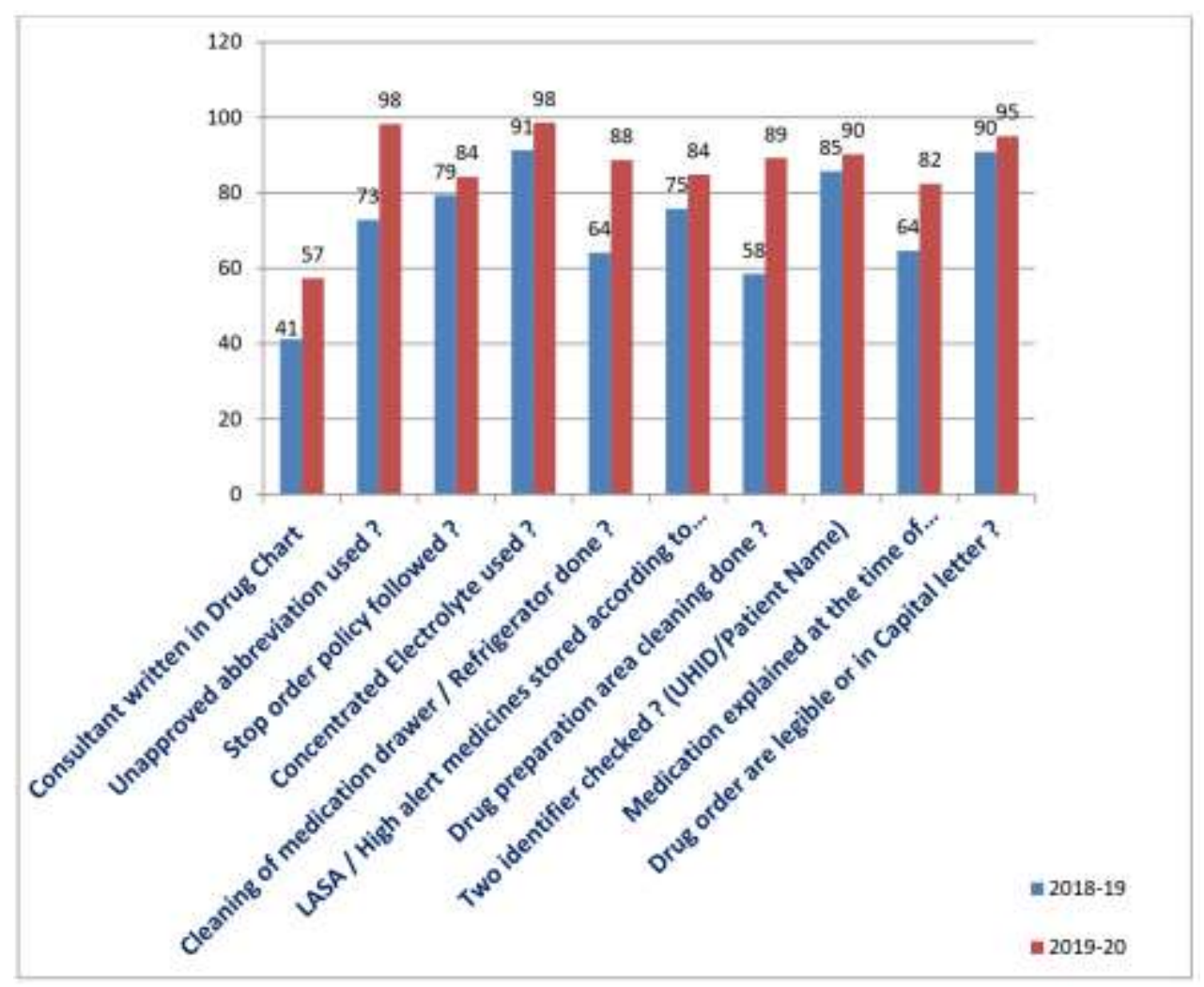

\section{Conclusion}

- After 19 month of project....we significantly improve the medication safety in our organization,

- The main thing is "Practice for 21 days and it will be habit" this is true word for this project....now medication management and medication safety is habit for our staffs (Doctor, Nurses and Pharmacists, Housekeeping)

- This work is now regular practice in our organization.

- We are still facing some issue like Consultant not written orders in drug chart, Medication room cleaning issue, Stop order policy, storage related issue...

- But our team regular train the staffs and continuously monitor all the standards of medication management....

- This project is continuous and we will defiantly more improve the medication management through Medication Tracer methodology.....

\section{REFERENCES}

1. Medication Management Tracer workbook. (2011). Joint Commission Resources.

2. Jacott, W. E. (2012). JACHO Advocates Improved Communication During Discharge. The Hospitalist. 2007.

3. Hendrick, E. C., Montanya, K. R., \& Griffith, N. (2007). Medication Tracers: A Systems Approach to Medication Safety. Hospital Pharmacy, 42(10), 916-920. 